\title{
Single-Port Bilateral Thoracscopic Dorsal Sympathectmy for Primary Hyperhidrosis: Long-Term Outcome
}

\author{
Aram Baram $^{1}$, Salam Al Bermani2 \\ ${ }^{1}$ Department of Thoracic and Cardiovascular Surgery, Faculty of Medical Sciences, School of Medicine, \\ University of Sulaimani, François Mitterrand Street, Sulaymaniyah, 46001, Iraq \\ ${ }^{2}$ Departement of Thoracic Surgery, Sulaimani Directorate of Health, Teaching Hospital, François Mitterrand \\ Street, Sulaymaniyah, 46001, Iraq \\ Email: ${ }^{*}$ aram.baramm@gmail.com, salamalbermani@gmail.com
}

Received 7 February 2014; revised 7 March 2014; accepted 15 March 2014

Copyright (C) 2014 by authors and Scientific Research Publishing Inc.

This work is licensed under the Creative Commons Attribution International License (CC BY).

http://creativecommons.org/licenses/by/4.0/

(c) (i) Open Access

\section{Abstract}

Background: Primary hyperhidrosis of the upper limbs is characterized by over activity of the eccrine sweat glands, primarily occurring on palmar, plantar and axillary regions. It is distressing and often socially disabling condition. Conservative treatment is usually not effective in controlling the disease mainly due to adverse effect of therapies. Endoscopic thoracic sympathectomy is considered as the treatment of choice, causing minimal morbidity and high success rates and patient satisfaction. Objective: The study aims to evaluate the long-term outcomes of single port bilateralthoracoscopic dorsal sympathectomyin treatment of primary hyperhidrosis of the palm and axilla. Methods: In this prospective study, performed primarily by a single surgeon, between August 1st 2010, and August 1st 2012, we performed 200 thoracoscopies on 100 patients with signs and symptoms of primary palmar and axillary hyperhidrosis in different age groups and in both genders, and all were studied and analyzed following treatment by single-port bilateral thoracoscopic dorsal sympathectomy in Sulaimani teaching hospital. Results: Total of 99 patients were satisfied with the outcome of post-surgery with a follow-up in the mean of 27 months and only one patient was reported no change in symptoms postoperatively. Complications reported in 6 patients inform of compensatory sweating $(n=2)$, Gestatory sweating $(n=1)$, Pneumothorax $(n=1)$, Intraoperative minor bleeding $(n=1)$ and only $1 \%$ failure rate was reported. No mortality was reported. Conclusions: Single port bilateral thoracoscopic thoracic sympathectomy is a very effective method in the management of primary hyperhidrosis. Single port provides less postoperative pain, safety, short operative time, and quick method for the treatment of primary hyperhidrosis in comparison to two or three ports approaches.

\footnotetext{
*Corresponding author.
} 


\section{Keywords}

Primary Hyperhidrosis, Single-Port, Sympathectomy, Long-Term Outcome

\section{Introduction}

Hyperhidrosis is defined as a pathologic condition of excessive sweating in amounts greater than physiologically needed for thermoregulation particularly in response to temperature and emotional stimuli [1]. It is a distressing, often socially disabling condition. Conservative treatment with topical or oral agents offers only minimal and temporary relief, and iontophoresis, which induce a nonspecific injury of the epidermis with abnormal keratinization and hyperkeratosis plugging of the orifices of the sweat gland, requiring long-term maintenance therapy to prevent recurrence [2]. Open surgical procedures involving severance or resection of the upper thoracic sympathetic chain $\left(T_{2}, T_{3}\right.$ and $T_{4}$ which are responsible for the sympathetic innervation of the upper limbs) through a posterior, transaxillary or supraclavicular approach were found to be very effective, but they were highly invasive and associated with a high rate of morbidity [3].

Since early 1970's, sympathectomy for hyperhidrosis became considerably safer with the introduction of the minimally invasive thoracoscopic technique of Kux [2], and it can now be offered to nearly all patients with severe hyperhidrosis [2] [3]. Several thoracoscopic methods have since been described, with different access sites and different operative approaches (resection of the chains or simple chain division over the ribs [4] or selective sympathectomy [5]).

Thoracoscopy provides a magnified view of the sympathetic trunk and adjacent anatomy for precise surgical resection of the sympathetic ganglia [6]. It has been proven safe, reliable, and cost-effective, offering long-term relief of symptoms [7] [8] and a significant reduction in the morbidity associated with open thoracotomy, supraclavicular, and paraspinal procedures without affecting its success rate [9] [10]. For length of hospital stay and morbidity reduced, improved the patient satisfaction which makes thoracoscopic approach more preferable [10] [11].

Hyperhidrosis is either focal which affecting the face, palms, axillae [1] (Figure 1) or generalized sweating, and it suggests a secondary etiology. The most common causes for the later one are excessive heat, obesity, systemic diseases such as infections, endocrine disorders, neuroendocrine tumors, malignancy, neurologic disorders, toxins, medications and previous spinal cord injuries, and these conditions should be diagnosed and treated medically and should not be treated with sympathectomy [1] [12] [13].

Additionally, some patients have craniofacial hyperhidrosis, or excessive blushing that is associated with severe emotional, occupational, and social distress [13].
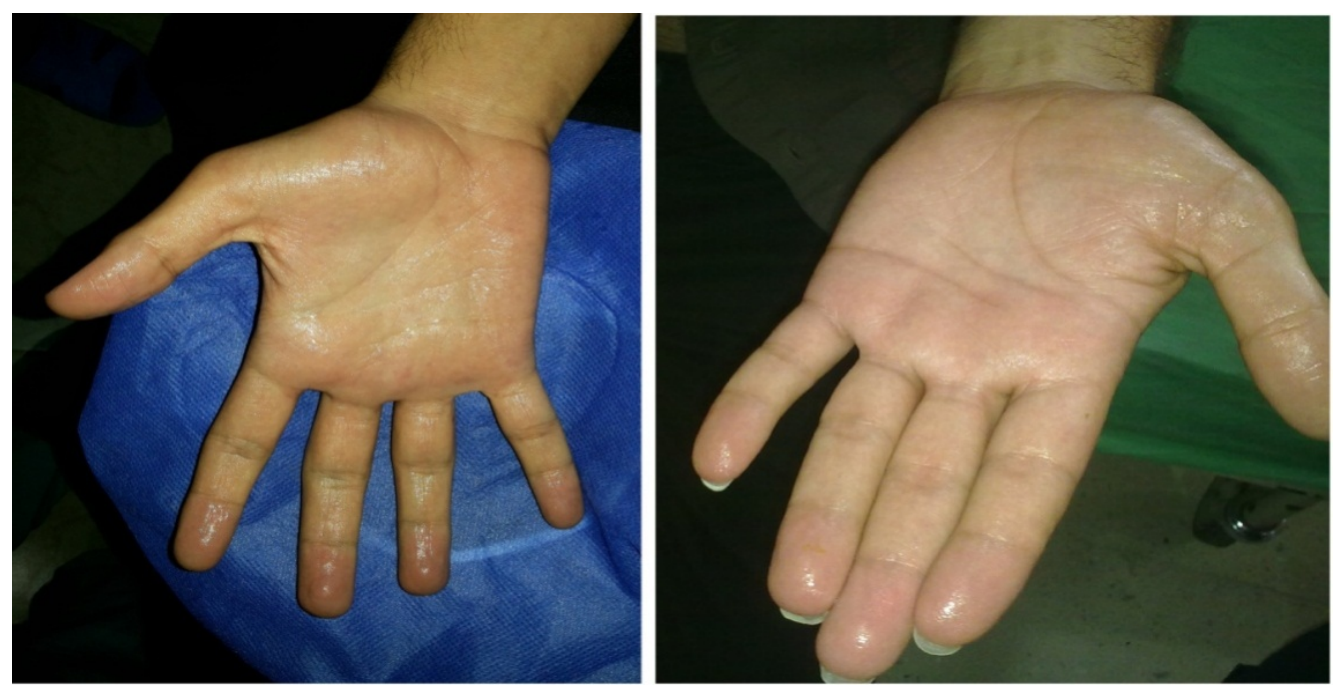

Figure 1. Palmar hyperhidrosis. 
The incidence of hyperhidrosis depends on the culture, on the climate, and on several subjective definitions [14]. It is believed that idiopathic primary hyperhidrosis affects $1 \%$ to $3 \%$ of the population with a predominance in countries that are near the Equator [12]-[15]. Hyperhidrosis affects both genders equally and affects predominantly adolescents or young adults [12]. Characteristically, the palmar symptoms start in early childhood, axillary symptoms in adolescence, and the craniofacial symptoms in adulthood, which is often, worsen with puberty [12].

\section{Patients and Methods}

\subsection{Patient's Collection}

Between August 1st 2010, and August 1st 2012, total of 200 patients with sign and symptom of primary palmar and axillary hyperhidrosis in different age groups and in both genders, all were studied and analyzed and prospectively followed after treatment by thoracoscopic dorsal sympathectomy in Sulaymaniyah teaching hospital a partner of school of Medicine of university of Sulaimani. Data were collected from operative reports and clinic visit.

\subsection{Patients' Presentation and Diagnostic Criteria}

Almost, all the patients were referred from dermatologists, all of them were suffering from palmar, axillary and plantar hyperhidrosis, but their main complaint was hand sweating that embarrassed them and interfered with their daily activity and jobs. Most of them considered themselves as handicapped that made them avoiding shaking hands or even wearing gloves. Precise distribution of sweating is reported in Table 1.

Diagnostic workup for all patients included clinical examination, full hematological, biochemical investigations to exclude any underlying cause. General assessment for all patients was done in the cooperation with the anesthesiologist and physician regarding fitness for general anesthesia and exclusion of other possible causes of the hyperhidrosis. Preoperative planning was done by revision of the operative technique details, confirmation of the side for operation and preparation of the surgical tools.

In the majority of cases, the diagnosis of primary hyperhidrosis can be established by obtaining a thorough history.

We classified our patients according to the criteria of Hyperhidrosis Disease Severity Scale (HDSS) [16] to rate the severity of the disease as in Table 2, which is disease-specific, quick, and easily-understood diagnostic tool that provide a qualitative measure of the severity of the patient's condition based on how it affects daily activities. The numbers in the scale indicate how responses should be scored. A score of 3 or 4 indicates severe hyperhidrosis. A score of 1 or 2 indicates mild or moderate hyperhidrosis [16].

As a part of measurement of treatment efficacy and patient satisfaction, the HDSS was used to evaluate the patient's response to surgery. The treatment will be successful if score improved from 4 or 3 to 2 or 1 or from a score 2 to 1 . Treatment failure can be defined as no changes in HDSS score after 1 month of therapy or lack of tolerability for the treatment [12] [16].

Table 1. Distribution of sweating.

\begin{tabular}{ccc}
\hline Affected area & Number & Percentage \\
\hline Axillary and Palmar & 64 & $64 \%$ \\
Axillary & 27 & $27 \%$ \\
Palmar & 9 & $9 \%$ \\
\hline
\end{tabular}

Table 2. Patient score the severity hyperhidrosis [16].

\begin{tabular}{cc}
\hline & Hyperhidrosis Disease Severity Scale (HDSS) \\
Score & "How would you rate the severity of your hyperhidrosis?" \\
\hline 1 & My sweating is never noticeable and never interferes with my daily activities \\
2 & My sweating is tolerable but sometimes interferes with my daily activities \\
4 & My sweating is barely tolerable and frequently interferes with my daily activities \\
\hline
\end{tabular}


Preoperative scoring showed that 95 patients (95\%) had score 4. Five patients had scored 3 (5\%) as showed in Table 3. All score 2 patients not operated on and referred back to dermatologist for further medical treatment.

\subsection{Technique}

The procedure was performed under general anesthesia and single lumen endotracheal intubation without selective ventilation, by which a low volume ventilation or block of ventilation in intervals were taken to collapse the lung. (Figure 2) No $\mathrm{CO}_{2}$ insufflation was used. The procedure done in the lateral decubitus position with the operation side up, with patient secured to table by supported stands. The upper arm elevated and abducted to clear the entry site and axilla, (Figure 3). After proper disinfection and draping, single dose of antibiotic in form of third generation Cephalosporin administered intravenously. The technique of single port used a $10 \mathrm{~mm}$ incision in the fifth intercostal space in the posterior axillary line as in (Figure 4). The skin incised at the upper border of the sixth rib, then blunt dissection of the intercostal muscles using blunt forceps down to the pleura which opened causing lung collapse. A laparoscopic trocar $(10 \mathrm{~mm})$ port is then inserted to keep the port opened. The disconnection of the mechanical ventilation leads to collapsing lung to avoid injury. Saturation of blood oxygen $\left(\mathrm{SO}_{2}\right)$ was carefully monitored during the operation. A zero degree thirty degree $10 \mathrm{~mm}$ thoracoscope (Figure 6 from Schöelly group for industrial and medical endoscope) [17], that connected to a video screen is introduced after testing its white balance, light source and camera. Initially, we inspect the lung pleura for any injury and adhesions. As, we were not using double lumen endotracheal intubation, we depend on blocking the ventilation in intervals according to the oxygen saturation, the operation was paused if saturation decrease until it reaches normal level. The sympathetic chain anatomy visualized along the neck of the ribs through the parietal pleura (Figure 5). Identification of the second, third and fourth ribs are now possible. Dissection and severing were carried out with high frequency electrocautery along the concerned rib width down to periosteum, taking care at level of $T_{2}$ to avoid current and heat diffusion to the satellite ganglion, Figure 6. For palmar hyperhidrosis transection of the symptahetic chain at ramai R2-4 performed. While for axillary sweating transection of R3, R4 and R5 was carried out. In both axillary and palmar hyperhidrosis R2, R3, R4 and R5 were transected. In cases of recurrence, R5, accessory fibers and the Kuntz nerve were located and coagulated. After checking for hemostasis the thoracoscope is withdrawn gradually and mechanical ventilation connected again to allow the lung to inflate under vision. Majority of patients show dry palms and axilla postoperatively (Figure 6).

The tidal volume back up again and a 20F chest tube was left in place for few hours that was removed after checking the chest radiographs. The usage of chest tube was experienced in the beginning of our study, in the first fifteen patients. Later on, we experienced no drain procedure, an ordinary chest tube inserted through the

\begin{tabular}{|c|c|c|c|c|c|c|}
\hline $\begin{array}{l}\text { Preoperative } \\
\text { Score }\end{array}$ & Number & Percentage & $\begin{array}{c}\text { Axillary and palmar } \\
\text { hyperhidrosis percentage }\end{array}$ & Axillary & Palmar & Total \\
\hline 4 & 95 & $95 \%$ & $\mathrm{n}=60(60 \%)$ & $\mathrm{n}=27(27 \%)$ & $\mathrm{n}=8(8 \%)$ & 95 \\
\hline 3 & 5 & $5 \%$ & $\mathrm{n}=4(4 \%)$ & Zero & $\mathrm{n}=1(1 \%)$ & 5 \\
\hline Total & 100 & $100 \%$ & 64 & 27 & 9 & 100 \\
\hline
\end{tabular}

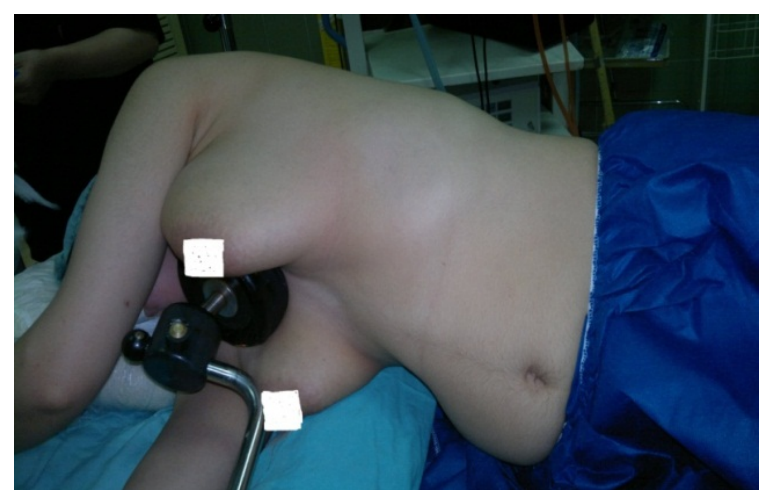

Figure 2. The position of patient for Thoracoscopy. 


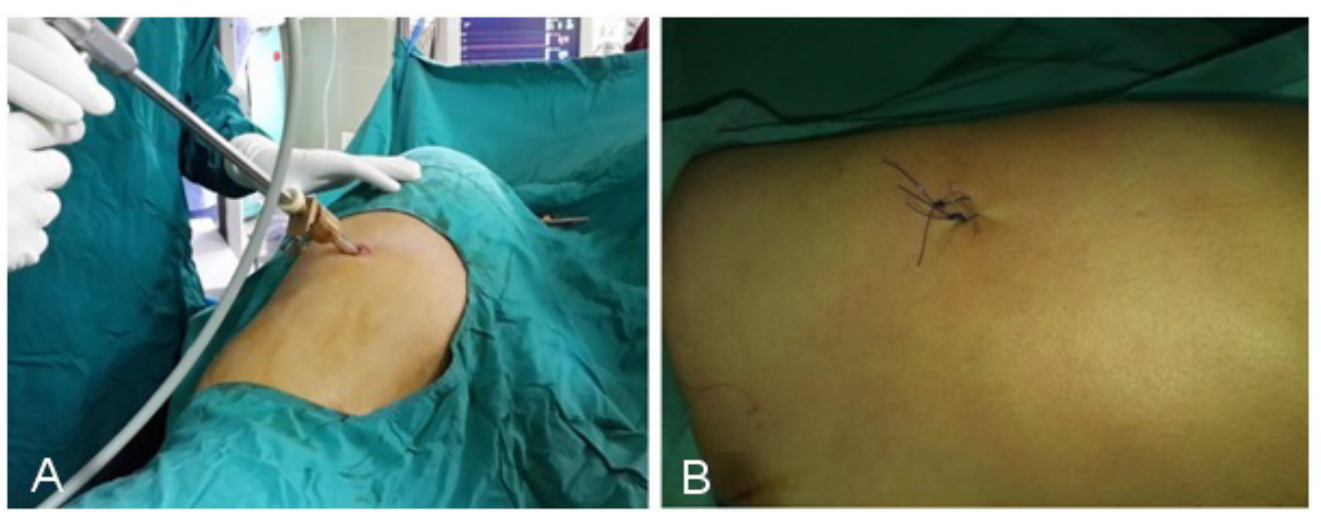

Figure 3. Site of entry, A show trocar that keep the port opened for the scope. B show the site after removal of drain in drain-less procedure.

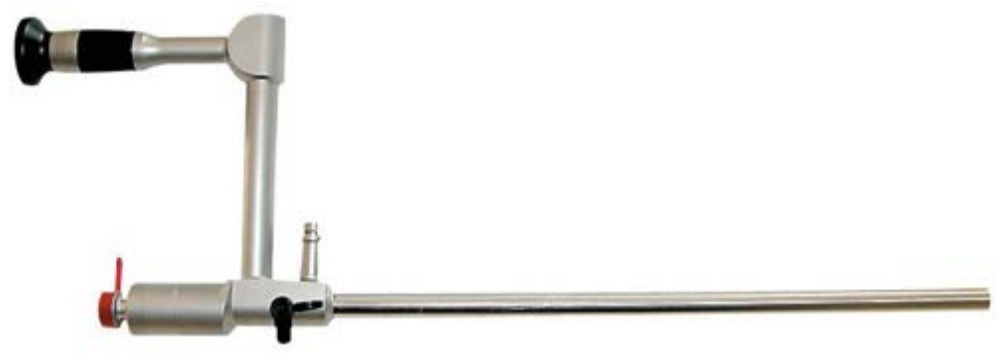

Figure 4. Zero degree, thirty degree $10 \mathrm{~mm}$ thoracoscope (Schöelly group for medical endoscopes) [17].
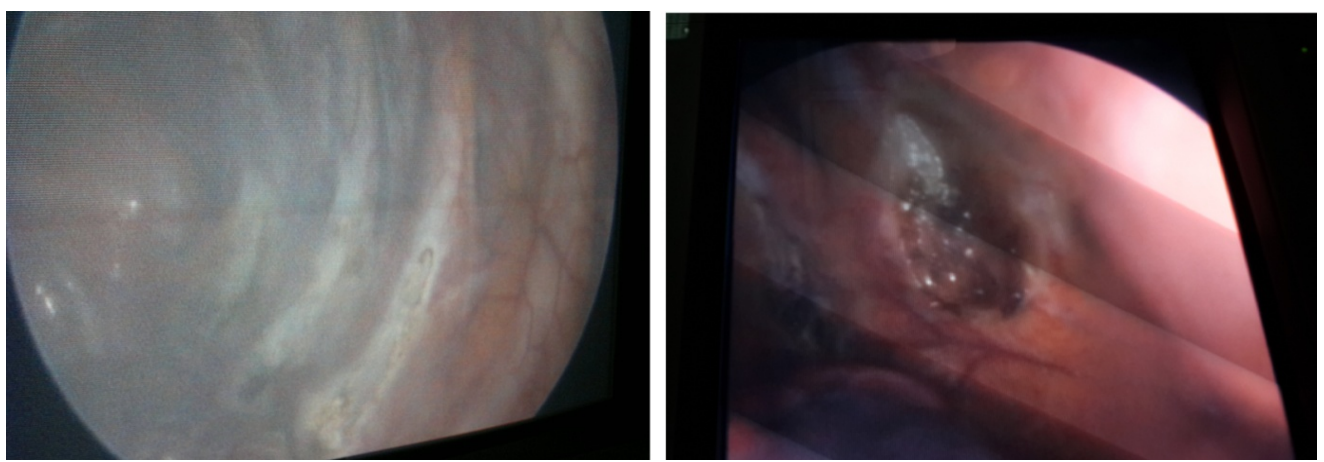

Figure 5. Sympathetic chain after severing by electro-cauterization.

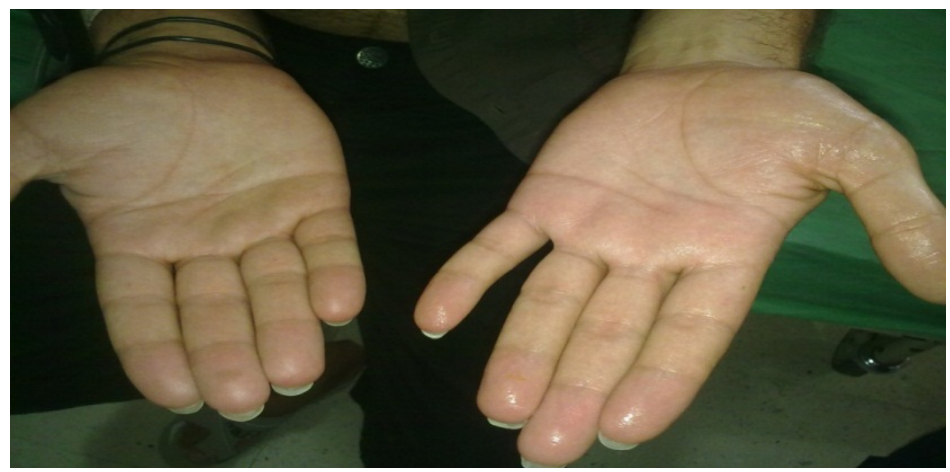

Figure 6. Difference between left sympathectomised and right non-sympathectomised hands. 
port that connected to an underwater seal system and then with positive ventilation the air evacuated and the chest tube removed after the incision secured with 2 stiches that closed immediately. The duration of the operation was (9 minutes to 1 hour) with a mean of 26.25 minutes.

\subsection{Results}

The study comprised 200 thoracoscopies on 100 patients, 80 females and 20 males, with female to male is 4:1. The patients aged from 18 to 40 years with mean age of 26.25 years. We performed 200 sympathectomies on 100 patients, female patients were 80, from which 69 patients had both axillary and palmar hyperhidrosis, 8 patients had axillary and only 3 palmar hyperhidrosis noticed. Male patients were 20, fourteen patients had both palmar and axillary hyperhidrosis, four patients with axillary hyperhidrosis and only 2 patients had palmar alone hyperhidrosis (Table 4).

\section{Complications}

The operation had relatively low rates of morbidity and no mortality. Ninety four patients show no complications postoperatively. Some complications occurred in six patients (6\%) and these complications included compensatory sweating in two cases, gustatory sweating in one case, one case developed pneumothorax required chest tube, intra-operative bleeding occurred in one case and one case show no improvement at all (Table 5).

\section{Follow Up and Satisfaction}

Follow up duration was in 6 - 48 months the mean of 27 months. Hyperhidrosis Disease Severity Scale (HDSS) used to assess the degree of satisfaction. All preoperative and operative answers were compaired and patients who show scale one post operatively considered as very satisfied and all postoperative score two considered as satisfied and postoperative score 3 and 4 considered as failure of surgery.

In 80 patients (80\%) were very satisfied with the results, 19 patients (19\%) were satisfied and only one patient (1\%) was dissatisfied and experienced no change in quality of life and the result was considered as failure, all patient who had post-operative complications had score 2, Table 6.

Table 4. Distribution of hyperhidrosis site affected according to the gender.

\begin{tabular}{|c|c|c|c|c|c|}
\hline \multirow{2}{*}{ Gender } & & \multicolumn{3}{|c|}{ Site Affected } & \multirow{2}{*}{ Total } \\
\hline & & Palmar and axillary & Axillary & Palmar & \\
\hline \multirow{3}{*}{ Female } & Frequency & 69 & 8 & 3 & 80 \\
\hline & Percent \% & $69 \%$ & $8 \%$ & $3 \%$ & $80 \%$ \\
\hline & $p$ value & \multicolumn{4}{|c|}{0.00067} \\
\hline \multirow{3}{*}{ Male } & Frequency & 14 & 4 & 2 & 20 \\
\hline & Percent \% & $14 \%$ & $4 \%$ & $2 \%$ & $20 \%$ \\
\hline & $p$ value & \multicolumn{4}{|c|}{0.00045} \\
\hline
\end{tabular}

Table 5. Frequency and percentage of complications.

\begin{tabular}{ccc} 
Type of complication & Frequency & Percent \% \\
\hline Compensatory sweating & 2 & 2 \\
Gustatory sweating & 1 & 1 \\
Pneumothorax & 1 & 1 \\
Intra-operative bleeding & 1 & 1 \\
Failure & 6 & 6 \\
Total & $p$ value $=0.054$
\end{tabular}


Table 6. Post-operative results and scores.

\begin{tabular}{ccccccc}
\hline Post-operative score & Number & Percentage & Very satisfied & Satisfied & Not satisfied(Failure) & Total \\
\hline 1 & 80 & $80 \%$ & 80 & & & 80 \\
2 & 18 & $18 \%$ & & 18 & & 18 \\
3 & & & & & 2 \\
4 & 2 & $2 \%$ & & & 1 & 2 \\
Total & 100 & $100 \%$ & 80 & 19 & 100 \\
\hline
\end{tabular}

$p$ value $=0.0006$.

\section{Discussion}

In 1951, for the first time the thoracic endoscopic sympathectomy was performed by Kux [18]. Recently, with the advances in video endoscopic technology, Video-Assisted Thoracoscopic Surgery (VATS) replaced open surgery for treating primary hyperhidrosis [1], with patients benefiting from a shorter hospital stay and recovery time [19], reduced morbidity rate [20], less pain, and better cosmetic results [21] [22].

However, postoperative pain after VATS is still significant. The main explanation of the pain relate to trauma of the thoracic wall caused while introducing the trocars into the intercostal space and periosteal lesions close to the rib head and under the sympathetic chain, secondary to lesion caused by transmission of heat from electrocautery [20] [23], and tertiary in two or three ports even if small could lead to patient discomfort and pain [24] [25]. In our series pain was not a significance pst operative problem neither in short or in long-term.

Patients were asked to indicate their degree of satisfaction, taking into account the result of hyperhidrosis symptoms and the onset of potential adverse effects. The overall satisfaction rate is dependent on the magnitude and impact on the quality of life of the problem solved by Endoscopic Thoracic Sympathectomy (ETS) [25]. Almost many authors revealed that patients recognize a high degree of patient satisfaction, as patients recognize that hyperhidrosis is a serious social problem that affect their interaction with other people, work, drive, or try to maintain their self-confidence and character [26]. Table 7 show the literature review of compensatory sweating and rate satisfaction.

In our study, 98\% of patients reported improvement and were very satisfied and satisfied with the result of single incision thoracoscopic approach, and willingness to shake hands postoperatively; $2 \%$ of patients remained dissatisfied with the result despite resolution of over sweating (mostly because of the adverse effect especially the compensatory sweating and failure of treatment and no change in symptoms).

Complications occurred in $6 \%$ of cases $(n=6)$, however no conversion to open surgery reported neither in previous studies, nor in our study [21]-[23].

The mean operative time in our study was 26.25 minutes, while in the study done by Chen et al. the mean operative time was 39.5 minutes, the prolonged operative time is mostly due to presence of adhesions between the chest wall and upper lobes and the bilateral ETS [24]-[26].

Compensatory sweating (CS) was the most common complication of endoscopic sympathectomy, with different incidence reported in previous studies, Chen et al. reported 60\% [24], Georghiou et al. reported 45\% [27], Lin et al. reported 86\% [20], Gossot et al. reported 86.4\% [5]. In our study, the incidence of compensatory hyperhidrosis was $2 \%(n=2)$ we investigate this very low rate of CS in our series but we couldn't find any reasonable explanation for that.

Compensatory sweating (CS) is characterized by the postoperative appearance of excessive perspiration in regions of the body where it had not been previously observed [28]. The hyperhidrosis is usually transferred from the hand or axillae to the trunk, groins, or lower extremities. It is almost inescapable and may lead to decreased patient satisfaction [29]. It is considered to be caused partly by an abnormal thermoregulatory response after sympathetic denervation [29].

Shoenfeld et al. and Drott et al. investigated total sweat volume and found that, despite a reduction in hand sweating, the total volume of sweat did not change, suggesting that the total volume in hands is equivalent to the CS in other parts of the body that are more sensitive to thermal changes than before surgery [29] [30].

Many authors reported that compensatory hyperhidrosis progressively disappears with time [30] [31], our experience demonstrates that compensatory sweating is not a source of discomfort for these patients because as sweating is diverted to less visible areas and the functional disability is less important. 
Table 7. Compensatory sweating and satisfaction after the Thoracoscopic Thoracic Sympathectomy.

\begin{tabular}{cccccccc}
\hline Investigator & Country & Year & No. & Mean Follow up & CS \% & Satisfied \% & Dissatisfied \% \\
\hline Rex LO [4] & Sweden & 1998 & 1152 & $38 \mathrm{~m}$ & 59.8 & 97.5 & 2.5 \\
Gossot D [5] & France & 2003 & 125 & $46 \mathrm{~m}$ & 86.4 & 92 & 8 \\
Lardinois [7] & Swiss & 2002 & 37 & $34 \mathrm{~m}$ & 72 & 95 & 5 \\
Herbst F [19] & Austria & 1994 & 270 & $36 \mathrm{~m}$ & 67.4 & 93.3 & 6.7 \\
Chiou TS [32] & Taiwan & 1999 & 91 & $22 \mathrm{~m}$ & 97 & 87 & 13 \\
Durate J [33] & Brazil & 1998 & 140 & $30 \mathrm{~m}$ & 5 & 96.5 & 3.5 \\
Lai Y [34] & China & 1997 & 72 & $18 \mathrm{~m}$ & 98.6 & 78 & 22 \\
Wali M [35] & Saudi Arabia & 2003 & 22 & $25 \mathrm{~m}$ & 12 & 94 & 6 \\
Katara A [36] & Singapore & 2006 & 25 & $23 \mathrm{~m}$ & 80 & 100 & 0 \\
\hline
\end{tabular}

No. = number of patients in study; CS: compensatory sweating; m: month.

Gustatory sweating (GS) is another well-recognized side effect after thoracic sympathectomy. It is defined as facial sweating during eating certain foods such as spicy food or acidic fruits like apples or oranges [37]. The causes are obscure, but it has been speculated that it may be caused by sprouting of vagal nerve fibers into the severed sympathetic chain [38].

The reported frequency of gustatory sweating varies considerably in the literatures. Some authors do not mention it [24] [32] [39] [40]. Lichtetal [37] reported gustatory sweating in 38\% especially in axillary hyperhidrosis that need extensive sympathectomy. Herbst et al. [19] reported it in a rate of 50.7\% in a series of 323 patients. The reported incidences of GS for various studies vary considerably, from 0\% to 38\% [24] [27] [37]-[41]. We reported gustatory sweating in 1\%. Treatment of this complication includes oral anticholinergic drugs, topical application of anticholinergics and aluminum chloride.

Postoperative pneumothorax was also seen more frequently among the literatures [37] [40] [41], however, it does not appear to be a major concern of most surgeons [42]-[45]. It is important to differentiate between two types of pneumothorax that can occur after sympathectomy. The first is the residual pneumothorax that can develop because of failure to exsufflate fully the air or gas from the thoracic cavity at end of sympathectomy [37]. A temporary little chest tube can be used to facilitate the exsufflation of air or gas to avoid this complication. The chest tube is aspirated while the anesthesiologist ventilates the patient manually, exerting continuous positive pressure for a few seconds before the drain is subsequently removed. This type of pneumothorax is reabsorbed spontaneously, disappearing in a few days. The patient should be reassured that this complication is minor, with no sequelae [37] [41].

The second type of pneumothorax is of greater concern. These pneumothoraces occurs secondary to a lung injury from a trocar or diathermy hook during the procedure or to a pulmonary lesion such as a bleb or emphysematous bulla that breaks during positive-pressure ventilation. Most of these pneumothoraces are treated with chest tube drainage [41].

In Table 8, the total rate of pneumothoraces (minor or requiring drain) varies from $0.3 \%$ to $25 \%$. The rate of pneumothoraces with drain varies from $0.3 \%$ to $6 \%$.

In our study, the number of residual pneumothorax was one patient (2\%), treated with chest drain and discharged 48 hours postoperatively. The use of chest drain was in the beginning of the study (first 15 thoracoscopies), later, we didn't use chest drain as with better management of exsufflation regarding using the drain at the end of the procedure in the synchronization with the anesthiologist during removal of this temporary drain.

We did not experience ahemothorax but one patient (2\%) developed intraoperative bleeding due to trauma to an intercostal vein that controlled intraoperatively with no need for chest drain at time or later on. Some investigators report cases of hemothorax without details! Rex et al. [4] reported four cases (0.3\%), Schmidt et al. [46], one case $(0.5 \%)$. Lin et al. [47] reported on two cases $(0.1 \%)$ of hemothorax, with one requiring chest tube drainage.Doolabh et al. [48] reported on three patients (1.6\%) who developed bleeding complications, with one patient requiring thoracoscopic re-exploration and the other patients requiring chest tube drainage.

Horner's syndrome is a significant complication that can occur in patients who undergo sympathectomy [23]. Although present in most series, we did not report it in our study. It can be total or partial, without myosis, and 
is caused by direct or indirect damage to $\mathrm{T}_{1}$. Direct damage can be due to improper localization of the second rib. Theoretically, the first rib is not identifiable within the thorax but can be palpated with an instrument [1] [23] [48]. Occasionally, the fat pad that covers the inferior part of the stellate ganglion may be lacking, leading to misidentification of the first and second ribs. In all series, this inadequate localization decreases with surgical experience [23].

Indirect damage to $T_{1}$ may be due to diffusion of monopolar high frequency current, thermal injury, excessive traction on the nerve during dissection, or resection of the nerve [43].

Recurrence after sympathectomy is found in almost all the literatures. Table 9: show the literature review of recurrence in relation to our study.

Many causes discussed by different authors for recurrence of the hyperhidrosis symptoms, including Kuntz nerve, variation in the sympathetic chain, improper identification of $\mathrm{T}_{2}$, pleural adhesions, the presence of an azygoslobe [44]. Other possible causes are an incomplete interruption of sympathetic chain and nerve regeneration [35]. In present study, recurrence reported in one case as failure of the ETS (1\%), the nerve of Kuntz mostly the possible and the blamed cause.

Table 8. Total rate of pneumothorax with or without drain in literature.

\begin{tabular}{cccccc}
\hline Investigator & Country & Year & No. & Total \% & Drain \% \\
\hline De Campos JR [1] & Brazil & 2003 & 378 & 2.4 & 1.8 \\
Rex LO [4] & Sweden & 1998 & 1152 & - & 1 \\
Gossot D [5] & France & 2001 & 467 & 2.5 & 0.8 \\
Chen Y [24] & China & 2008 & 20 & - & 10 \\
GeorghiouGP [27] & Israel & 2004 & 176 & - & 2.3 \\
Licht PB [37] & Denmark & 2004 & 158 & 25 & 6.2 \\
Dumont P [41] & France & 2004 & 124 & 1.3 & 2.4 \\
Baumgartner FJ [49] & USA & 2003 & 309 & 0.45 & 0.3 \\
Lin TS [46] & Taiwan & 2001 & 2200 & - & - \\
Schmidt J [47] & Germany & 2006 & 178 & - & 2.2 \\
Michael O [50] & UK & 2006 & 179 & -2.7 \\
Rathinam S [51] & UK & 2008 & 100 & - & 5
\end{tabular}

No. $=$ number of patients in study.

Table 9. Rate of recurrence and reoperation after sympathectomy.

\begin{tabular}{cccccc}
\hline Investigator & Country & Year & No. & Recurrence \% & Reoperation \% \\
\hline De Campos JR [1] & Brazil & 2003 & 378 & 7.6 & 2.1 \\
Rex LO [4] & Sweden & 1998 & 1152 & 3.2 & 3.2 \\
Gossot D [5] & France & 2001 & 467 & 2.3 & 2.3 \\
Lin TS [20] & Taiwan & 2001 & 2200 & 1.0 & 1.0 \\
Chen Y [24] & China & 2008 & 20 & 0.0 & 0.0 \\
Georghiou GP [27] & Israel & 2004 & 176 & 0.0 & 0.0 \\
Baumgartner FJ [30] & USA & 2003 & 309 & 1.9 & 0.0 \\
Licht PB [37] & Denmark & 2004 & 158 & 2.5 & 0.4 \\
Dumont P [41] & France & 2004 & 124 & 3.6 & 1.6 \\
Steiner Z [44] & Israel & 2007 & 265 & 0.0 & 0.0 \\
Ueyama T [45] & Japan & 2001 & 7017 & 0.0 & 0.1 \\
Schmidt J [47] & Germany & 2006 & 178 & 0.0 \\
\hline
\end{tabular}

No. = number of patients in study. 
We used the zero degree/ thirty degree $10 \mathrm{~mm}$ thoracoscope (from Schöelly group for medical endoscopes) for single port, that never used but other authors. Some authors reported usage of other thoracoscope that was 5 $\mathrm{mm}$ instead of $10 \mathrm{~mm}$ scope so that only $5 \mathrm{~mm}$ trocarsare required, resulting in smaller wounds [48]. However, the image quality with a $5 \mathrm{~mm}$ scope, while adequate, is inferior to that obtained from $10 \mathrm{~mm}$ scope that may limit the procedure unless the surgeon has gained considerable experience with those procedures [52].

We favor the lateral decubitus position for the procedure to operate bilaterally in one session. The supine position has the advantage that both sides can be operated on in one session even with one skin preparation. However, in supine position the lung, even with if fully collapsed falls posteriorly, obscuring the view, so the need for further port to retract the lung is obvious [52]. Some authors reported the use for $\mathrm{CO}_{2}$ insufflation in the pleural cavity even with collapsed lung [30].

The trans-axillary approach need the patient to be in supine position with arm abducted and externally rotated that need more manipulation for them that even with the use of muscle relaxants, the biceps could be very tight and make the field not so comfortable for the operator [53]. Some authors reported a complication of brachial plexopathy [53].

\section{Conclusions}

Endoscopic approach for dorsal sympathectomy is a minimally invasive, highly successful treatment and good satisfactory method of treatment for the patients with primary hyperhidrosis of the upper limbs. Almost, there was no mortality and low incidence of morbidity.

Single port approach with one side in session offers good, cosmetic results and avoids the chest wall complications that often seen in two or three ports approach. Posterior axillary line approach is easier, with clear field for the operator. The $10 \mathrm{~mm}$ scope gives the operator more control and easy performance.

\section{Acknowledgments}

We would like to acknowledge all our personnel who assisted in serving our patients.

\section{Conflict of Interest}

The authors declare that they have no competing interests.

\section{Authors Contribution}

Aram Baram: surgeon performed the operations, study design, follow-up. Salam A Al Bermani: Data collection, statistical analysis

\section{References}

[1] De Campos, J.R., Kauffman, P., Ede Campos, W., Andrade, F.L.O., Kusniek, S., Wolosker, N. and Jatene, F.B. (2003) Quality of Life, before and after Thoracic Sympathectomy: Report on 378 Operated Patients. The Annals of Thoracic Surgery, 76, 886-891. http://dx.doi.org/10.1016/S0003-4975(03)00895-6

[2] Hsu, C.P., Chen, C.Y., Lin, C.T., Wang, J.H., Chen, C.L. and Wang, P.Y. (1994) Video Assisted Thoracoscopic T 2 Sympathectomy for Hyperhidrosis Palmaris. Journal of the American College of Surgeons, 178, 59-64.

[3] Kux, M. (1978) Thoracic Endoscopic Sympathectomy in Palmar and Axillary Hyperhidrosis. Archives of Surgery, 113, 264-266. http://dx.doi.org/10.1001/archsurg.1978.01370150036005

[4] Rex, L.O., Drott, C., Claes, G., Göthberg, G. and Dalman, P. (1998)The Bora’s Experience of Endoscopic Thoracicsympathicotomy for Palmar, Axillary, Facial Hyperhidrosis and Facial Blushing. European Journal of Surgery, 580, 23-26.

[5] Gossot, D., Galetta, D., Pascal, A., Debrosse, D., Galiandro, R., Girard, P., Stern, J.-B. and Grunenwald, D. (2003) Long-Term Results of Endoscopic Thoracic Sympathectomy for Upper Limb Hyperhidrosis. The Annals of Thoracic Surgery, 75, 1075-1079. http://dx.doi.org/10.1016/S0003-4975(02)04657-X

[6] Hashmonai, M., Kopelman, D. and Schein, M. (1994) Thoracoscopic versus Open Supraclavicular Upper Dorsal Sympathectomy: A Prospective Randomized Trial. European Journal of Surgery, 572, 13-16.

[7] Lardinois, D. and Ris, H.B. (2002) Minimally Invasive Video-Endoscopic Sympathectomy by Use of a Transaxillary Single-Port Approach. European Journal of Cardio-Thoracic Surgery, 21, 67-70. 
http://dx.doi.org/10.1016/S1010-7940(01)01042-9

[8] Krasna, M.J., Demmy, T.L., McKenna, R.J. and Mack, M.J. (1998) Thoracoscopic Sympathectomy: The US Experience. European Journal of Surgery, 580, 19-21.

[9] Zacherl, J., Imhof, M., Huber, E.R., Plas, E.G., Herbst, F., Jakesz, R. and Füger, R. (1999) Video Assistance Reduces Complication Rate of Thoracoscopicsympathectomy for Hyperhidrosis. The Annals of Thoracic Surgery, 68, 1177 1181. http://dx.doi.org/10.1016/S0003-4975(99)00718-3

[10] Mockus, M.B., Rutherford, R.B., Rosales, C., et al. (1987) Sympathectomy for Causalgia. Patient Selection and Long-Term Results. Archives of Surgery, 122, 668-672. http://dx.doi.org/10.1001/archsurg.1987.01400180050009

[11] Drott, C. and Göran, G. (1995) Endoscopic Trans-Thoracic Sympathectomy: An Efficient and Safe Method for the Treatment of Hyperhidrosis. Journal of the American Academy of Dermatology, 33, 78-81. http://dx.doi.org/10.1016/0190-9622(95)90015-2

[12] Cerfolio, R.J., De Campos, J.R.M., Bryant, A.S., Connery, C., Miller, D., De Camp, M., McKenna, R.J. and Krasna, M. (2011) The Society of Thoracic Surgeons Expert Consensusfor the Surgical Treatment of Hyperhidrosis. The Annals of Thoracic Surgery, 91, 1642-1648. http://dx.doi.org/10.1016/j.athoracsur.2011.01.105

[13] Nowell, S., Vince, B., Alian, D., Chih, H., Charles, L., Mark, L., Kevin, C. and Greg, S. (2007) A Comprehensive Approach to the Recognition, Diagnosis, and Severity-Based Treatment of Focal Hyperhidrosis: Recommendations of the Canadian Hyperhidrosis Advisory Committee. Dermatologic Surgery, 33, 908-923. http://dx.doi.org/10.1111/j.1524-4725.2007.33192.x

[14] Adar, R., Kurchin, A., Zweig, A. and Mozes, M. (1977) Palmar Hyperhidrosis and Its Surgical Treatment: A Report of 100 Cases. Annals of Surgery, 186, 34-41. http://dx.doi.org/10.1097/00000658-197707000-00006

[15] Leung, A.K., Chan, P.Y. and Choi, M.C. (1999) Hyperhidrosis. International Journal of Dermatology, 38, $561-567$. http://dx.doi.org/10.1046/j.1365-4362.1999.00609.x

[16] Solish, N., Bertucci, V., Dansereau, A., Hong, H.C.H., Lynde, C., Lupin, M., Smith, K.C. and Storwick, G. (2007) A Comprehensive Approach to the Recognition, Diagnosis and Severity-Based Treatment of Focal Hyperhidrosis: Recommendations of the Canadian Hyperhidrosis Advisory Committee. Dermatologic Surgery, 33, 908-923. http://dx.doi.org/10.1111/j.1524-4725.2007.33192.x

[17] Schöelly Group for Industrial and Medical Endoscopes (2013) Thoracoscope Zero Degree/Thirty Degree. http://www.schoelly-group.com/en/Products/List/Medical-Endoscopy-8/Private-Label-Endoscopy-Products

[18] Kux, E. (1951) The Endoscopic Approach to the Vegetative Nervous System and Its Therapeutic Possibilities: Especially in Duodenal Ulcer, Angina Pectoris, Hypertension and Diabetes. Chest, 20, 139-147. http://dx.doi.org/10.1378/chest.20.2.139

[19] Herbst, F., Plas, E.G., Fugger, R. and Fritsch, A. (1994) Endoscopic Thoracic Sympathectomy for Primary Hyperhidrosis of the Upper Limbs. A Critical Analysis and Long-Term Results of 480 Operations. Annals of Surgery, 220, 86-90. http://dx.doi.org/10.1097/00000658-199407000-00012

[20] Lin, T.S., Huang, L.C., Wang, P.H. and Lai, C.Y. (2001) Video-Assisted Thoracoscopic $\mathrm{T}_{2}$ Sympathetic Block by Clipping for Palmar Hyperhidrosis: Analysis of 52 Cases. Journal of Laparoendoscopic \& Advanced Surgical Techniques, 11, 59-62. http://dx.doi.org/10.1089/109264201750162211

[21] Ohta, M. and Ishikawa, K. (2006) Minimally Invasive Surgery for Primary Hyperhidrosis. Japanese Journal of Thoracic Surgery, 59, 736-741.

[22] Hashmonai, M., Kopelman, D. and Assalia, A. (2000) The Treatment of Primary Palmar Hyperhidrosis: A Review. Surgery Today, 30, 211-218. http://dx.doi.org/10.1007/s005950050047

[23] Dumont, P., Denoyer, A. and Robin, P. (2004) Long-Term Results of Thoracoscopic Sympathectomy for Hyperhidrosis. Annals of Thoracic Surgery, 78, 1801-1807. http://dx.doi.org/10.1016/j.athoracsur.2004.03.012

[24] Chen, Y., Ye, W., Yang, W., Shi, L., Guo, X., Xu, Z. and Qian, Y. (2009) Uniportal versus Biportal Video-Assisted Thoracoscopic Sympathectomy for Palmar Hyperhidrosis. Chinese Medical Journal, 122, 1525-1528.

[25] Drott, C. (2003) Results of ETS on Hyperhidrosis, Facial Blushing, Angina Pectoris, Vascular Disorders and Pain Syndromes of the Hand and Arm. Clinical Autonomic Research, 13, i26-i30. http://dx.doi.org/10.1007/s10286-003-1109-z

[26] Prasad, A., Ali, M. and Kaul, S. (2010) Endoscopic Thoracic Sympathectomy for Primary Palmar Hyperhidrosis. Surgical Endoscopy, 24, 1952-1957. http://dx.doi.org/10.1007/s00464-010-0885-5

[27] Georghiou, G.P., Berman, M., Bobovnikov, V., Vidne, B.A. and Saute, M. (2004) Minimally Invasive Thoracoscopic Sympathectomy for Palmar Hyperhidrosis via a Transaxillary Single-Port Approach. Interactive Cardiovascular and Thoracic Surgery, 3, 437-441. http://dx.doi.org/10.1016/j.icvts.2004.03.003

[28] Li, X., Tu, Y.R., Lin, M., Lai, F.C., Chen, J.F. and Dai, Z.J. (2008) Endoscopic Thoracic Sympathectomy for Palmar Hyperhidrosis: A Randomized Control Trial Comparing $\mathrm{T}_{3}$ and $\mathrm{T}_{2-4}$ Ablation. Annals of Thoracic Surgery, 85, 1747- 
1751. http://dx.doi.org/10.1016/j.athoracsur.2008.01.060

[29] Shoenfeld, Y., Shapiro, Y., Machtiger, A. and Magazanik, A. (1976) Sweat Studies in Hyperhidrosis Palmaris and Plantaris. A Survey of 60 Patients before and after Cervical Sympathectomies. Dermatologica, 152, 257-262. http://dx.doi.org/10.1159/000251250

[30] Drott, C., Gothberg, G. and Claes, G. (1995) Endoscopic Transthoracic Sympathectomy: An Efficient and Safe Method for the Treatment of Hyperhidrosis. Journal of the American Academy of Dermatology, 33, 78-81. http://dx.doi.org/10.1016/0190-9622(95)90015-2

[31] Byrne, J., Walsh, T.N. and Hederman, W.P. (1990) Endoscopic Transthoracic Electrocautery of the Sympathetic Chain for Palmar and Axillary Hyperhidrosis. British Journal of Surgery, 77, 1046-1049. http://dx.doi.org/10.1002/bjs.1800770931

[32] Chiou, T.S. and Chen, S.C. (1999) Intermediate-Term Results of Endoscopic Transaxillary $T_{2}$ Sympathectomy for Primary Palmar Hyperhidrosis. British Journal of Surgery, 86, 45-47. http://dx.doi.org/10.1046/j.1365-2168.1999.00992.x

[33] Durate, J. and Kux, P. (1998) Improvement in Video-Endoscopic Sympathectomy for the Treatment of Palmar, Axillary, Facial and Palmar Hyperhidrosis. European Journal of Surgery, 164, 9-11. http://dx.doi.org/10.1080/11024159850191058

[34] Lai, Y., Yang, L., Chio, C. and Chen, H. (2004) Complications in Patients with Palmar Hyperhidrosis Treated with Transthoracic Endoscopic Sympathectomy. Archivos de Bronconeumología, 40, 17-19.

[35] Wali, M. (2003) Early Experience with Thoracoscopic Sympathectomy for Palmar Hyperhidrosis. Annals of Thoracic and Cardiovascular Surgery, 9, 351-354.

[36] Katara, A.N., Domino, J.P., Cheah, W.-K., So, J.B, Ning, C. and Lomanto, D. (2007) Comparing $T_{2}$ and $T_{2}-T_{3}$ Ablation in Thoracoscopic Sympathectomy for Palmar Hyperhidrosis: A Randomizes Control Trial. Surgical Endoscopy, 21, 1768-1771.

[37] Licht, P.B. and Pilegaard, H.K. (2004) Severity of Compensatory Sweating after Thoracoscopic Sympathectomy. Annals of Thoracic Surgery, 78, 427-431. http://dx.doi.org/10.1016/j.athoracsur.2004.02.087

[38] Hashmonai, M., Kopelman, D., Kein, O. and Schein, M. (1992) Upper Thoracic Sympathectomy for Primary Palmar Hyperhidrosis: Long-Term Follow-Up. British Journal of Surgery, 79, 268-271. http://dx.doi.org/10.1002/bjs.1800790329

[39] Riet, M., Smet, A.A., Kuiken, H., Kazemier, G. and Bonjer, H.J. (2001) Prevention of Compensatory Hyperhidrosis after Thoracoscopic Sympathectomy for Hyperhidrosis. Surgical Endoscopy, 15, 1159-1162. http://dx.doi.org/10.1007/s004640090097

[40] Kao, M.C., Chen, Y.L., Lin, J.Y., Hsieh, C.S. and Tsai, J.C. (1996) Endoscopic Sympathectomy Treatment for Craniofacial Hyperhidrosis. JAMA Surgery, 131, 1091-1094. http://dx.doi.org/10.1001/archsurg.1996.01430220085019

[41] Dumont, P. (2008) Side Effects and Complications of Surgery for Hyperhidrosis. Thoracic Surgery Clinics, 18, 193207. http://dx.doi.org/10.1016/j.thorsurg.2008.01.007

[42] Furlan, A.D., Mailis, A. and Papagapiou, M. (2000) Are We Paying a High Price for Surgical Sympathectomy? A Systematic Literature Review of Late Complications. Journal of Pain, 1, 245-257. http://dx.doi.org/10.1054/jpai.2000.19408

[43] Miller, D.L. and Force, S.D. (2007) Outpatient Microthoracoscopic Sympathectomy for Palmar Hyperhidrosis. Annals of Thoracic Surgery, 83, 1850-1853. http://dx.doi.org/10.1016/j.athoracsur.2006.11.030

[44] Steiner, Z., Kleiner, O., Hershkovitz, Y., Mogilner, J. and Cohen, Z. (2007) Compensatory Sweating after Thoracoscopic Sympathectomy: An Acceptable Trade-Off. Journal of Pediatric Surgery, 42, 1238-1242. http://dx.doi.org/10.1016/j.jpedsurg.2007.02.015

[45] Ueyama, T., Matsumoto, Y., Abe, Y., Yuge, O. and Iwai, T. (2001) Endoscopic Thoracic Sympathicotomy in Japan. Annales Chirurgiae et Gynaecologiae, 90, 200-202.

[46] Lin, T.S., Wang, N.P. and Huang, L.C. (2001) Pitfalls and Complication Avoidance Associated with Transthoracic Endoscopic Sympathectomy for Primary Hyperhidrosis (Analysis of 2200 Cases). International Journal of Surgical Investigation, 2, 377-385.

[47] Schmidt, J., Bechara, F.G., Altmeyer, P. and Zirngibl, H. (2006) Endoscopic Thoracic Sympathectomy for Severe Hyperhidrosis: Impact of Restrictive Denervation on Compensatory Sweating. Annals of Thoracic Surgery, 81, 1048-1055. http://dx.doi.org/10.1016/j.athoracsur.2005.09.046

[48] Doolabh, N., Horswell, S., Williams, M., et al. (2004) Thoracoscopic Sympathectomy for Hyperhidrosis: Indications and Results. Annals of Thoracic Surgery, 77, 410-414. http://dx.doi.org/10.1016/j.athoracsur.2003.06.003

[49] Baumgartner, F.J. and Toh, Y. (2003) Severe Hyperhidrosis: Clinical Features and Current Thoracoscopic Surgical Management. Annals of Thoracic Surgery, 76, 1878-1883. http://dx.doi.org/10.1016/S0003-4975(03)01069-5 
[50] Murphy, M.O., Ghosh, J., Khwaja, N., Murray, D., Halka, A.T., Carter, A., Turner, N.J. and Walker, M.G. (2006) Upper Dorsal Endoscopic Thoracic Sympathectomy: A Comparison of One- and Two-Port Ablation Techniques. European Journal of Cardio-Thoracic Surgery, 30, 223-227. http://dx.doi.org/10.1016/j.ejcts.2006.04.016

[51] Rathinam, S., Nanjaiah, P., Sivalingam, S. and Rajesh, P.B. (2008) Excision of Sympathetic Ganglia and the Rami Communicates with Histological Confirmation Offers Better Early and Late Outcomes in Video Assisted Thoracoscopic Sympathectomy. Journal of Cardiothoracic Surgery, 3, 50. http://dx.doi.org/10.1186/1749-8090-3-50

[52] Tai, Y.P., Lee, M. and Li, M. (1996) Thoracoscopic Sympathectomy for Palmar Hyperhidrosis: Hong Kong Early Experience. Hong Kong Medical Journal, 2, 315-318.

[53] Chi, L.J., Hsu, J.L., Tsai, M.D. and Wang, A. (2003) Position-Related Brachial Plexopathy after Thoracoscopic Sympathectomy: A Case Report. Acta Neurologica Taiwanica, 12, 85-88. 